\title{
Imbas Konsistensi Hukuman Mati pada Hubungan Bilateral dalam Kasus Narkoba
}

\author{
Oleh: Moh. Rosyid \\ mrosyid72@yahoo.co.id
}

\begin{abstract}
This article discusses about the debate over death penalty in the drug abuse cases. The Constitutional Court on October 30th, 2007 on the judicial review of Article 80 of the Law No 22/1997 on Drug declared that death penalty is not violating the Constitution which guarantees the right to life. Furthermore, Indonesia has ratified the International convention on narcotics and psychotropic. On the other hand, the opponent of death penalty argues that death penalty violates Article 28A of the Amendment of the Constitution that all people have the right to life. Secondly, death penalty is cruel and inhumane. Thirdly, there is possibility for false trial, and fourth, death penalty is not in-line with the reformation of penal law which imposes on restorative justice instead of retributive. Fifth, the effect is just a myth and sixth, the family becomes co-victim. Seventh, death penalty also threatened Indonesian living abroad and the last, death penalty cause the loss of Indonesia in International relations.
\end{abstract}

Keywords: death penalty, drugs, protection

\section{A. Pendahuluan}

Dalam catatan sejarah, hukuman mati di Indonesia pertama dijatuhkan pada November 1967 terhadap Letkol Untung dan Mayor Mulyono. Keduanya terlibat G 30 S 1965. Setelah diundangkannya UU Nomor 9 Tahun 1976 tentang Narkotika, hukuman tersebut pertama kali dijatuhkan Pengadilan Negeri Langsa, Aceh Timur terhadap dua warga Taiwan, Chang Sow Ven dan Lee Wah Ceng. Keduanya terbukti menyelundupkan 9,5 kg heroin melalui perairan (padahal sekitar 1,0 gram sabu dapat digunakan lima orang). Hukuman mati berikutnya dijatuhkan pada Imran bin Mohamad Zein karena membajak pesawat Garuda Airways kode DC-9 Woyla (peristiwa Woyla) tahun 1981. Imran sebagai pemimpin kelompok ekstrimis komando jihad divonis 
Pengadilan Negeri Jakarta Pusat dihukum mati (digantung) tahun 1981. Dua teman Imran, Maman Kusmayadi dieksekusi tahun 1985 dan Salman Hafidz dieksekusi tahun 1986. Tahun 1986 S jam Kamaruzzaman dieksekusi mati bertanggung jawab atas tragedi G 30 S yang membunuh 6 jenderal TNI Angkatan Darat. Tahun 2001, Fabianus Tibo, Marinus Riwu, dan Daminggus Da Silva ketiganya divonis mati dan dieksekusi mati tahun 2006 karena pembunuhan berencana, penganiayaan, dan perusakan tiga desa di Poso, Sulawesi Tengah. Vonis Tibo, dkk mengundang reaksi dari Abdurrahman Wahid, Kardinal Julius Darmaatmadja, dan Tahta Suci Vatikan ikut mengecamnya. Hukuman mati masih terjadi di Indonesia hingga ditulisnya naskah ini. Pro-kontra hukuman mati masing-masing memiliki argumen hukum.

Dampak yang dahsyat atas narkoba, sehingga Kepala Badan Narkotika Nasional (BNN) Komjen Pol Budi Waseso menyatakan kewenangan BNN untuk diperkuat setara dengan Komisi Pemberantasan Korupsi (KPK) agar upaya pemberantasan narkotika dan obat terlarang bisa optimal. Selama ini kewenangannya setingkat dirjen dalam kementerian sehingga kesulitan berkoordinasi langsung dengan para menteri untuk memberantas narkoba secara masif. Menko Polhukam (saat itu) Luhut Binsar Pandjaitan menyatakan tatkala meninjau Gedung BNN di Jakarta, Kamis 10 Maret 2016 bahwa pemerintah sedang mengkaji ulang struktur organisasi Badan Narkotika Nasional (BNN) hingga setingkat kementerian. Hal ini untuk menekan peredaran narkoba yang semakin masif hingga menelan korban jiwa 30-50 orang per hari dan peredarannya melibatkan narapidana. Presiden Jokowi menyetujui untuk mengkaji ulang organisasi BNN. Pemerintah juga akan meningkatkan sarana dan prasarana BNN setingkat kementerian (misalnya jumlah anjing pelacak), penambahan personil yang pada 2016 hanya berjumlah 4.600 orang secara nasional idealnya 74.000, dan meningkatkan kualitas laboratorium BNN. Kepala BNN Komjen Pol Budi Waseso menyatakan, BNN mengamankan 6 ton sabu setiap tahun meski 30 ton sabu lolos dan beredar di masyarakat. Wacana BNN setingkat kementerian mencuat sejak era Kepala BNN Gories Mere, tapi Presiden SBY (saat itu) menolaknya. Menurut Deputi Kelembagaan dan Tata Laksana Kementerian 
Pendayagunaan Aparatur Negara dan Reformasi Birokrasi (Kemenpan RB) Rini Widyantini mengatakan, dari aspek kelembagaan, idealnya lembaga pemerintah nonkementerian (LPNK) seperti BNN diisi pejabat karier, bukan pejabat setingkat menteri karena keberadaan LPNK bertujuan membantu mempercepat pelaksanaan program dan pencapaian target pemerintah. Dalam UU Nomor 5 Tahun 2014 tentang Aparatur Sipil Negara (ASN), kepala LPNK harus diisi oleh orang yang berkualifikasi jabatan pimpinan tinggi utama, jabatan tertinggi dalam struktur kepegawaian. Meski ada pula LPNK yang fasilitasnya setingkan kementerian, yakni Badan Nasional Penanggulangan Bencana (BNPB) karena amanah UU yang melahirkan BNPB (Kompas, 11 Maret 2016).

Kasus penegakan hukum tak membuat jera pelaku penyelundup, penjual, dan pengguna narkoba di Indonesia. Dalam data ini, empat bandar sabu divonis hukuman mati sebagaimana tuntutan jaksa oleh Majelis Hakim Pengadilan Negeri Banda Aceh, Senin 21 Desember 2015 di Banda Aceh, Aceh. Keempat bandar warga Aceh Timur, yakni Abdullah (36 tahun), Hasan Basri (35 tahun), Samsul Bahri (36 tahun), dan Hamdani (35 tahun). Mereka dinyatakan bersalah atas kepemilikan sabu seberat 78,1 kg karena membeli, mengedarkan, dan memiliki narkoba. Mereka dikenai Pasal 112, 113, dan 114 ayat (2) jo Pasal 132 ayat (1) UU Nomor 35 Tahun 2009 tentang Narkotika. Majelis hakim diketuai Sulthoni, Eddy S dan Makaroda sebagai anggota. Awalnya mereka ditangkap BNN di Dusun Nabok, Desa Lue Bu, Peureulak, Aceh Timur 15 Februari 2015 dengan mobilnya. Sabu dipasok dari Malaysia lewat jalur laut Peureulak. Dalih hakim, tindakan terpidana berpotensi merusak generasi muda. Pengacara terdakwa, Muhammad Syafii Saragih naik banding. Pada waktu yang bersamaan, PN Banda Aceh juga menjatuhkan hukuman seumur hidup kepada Sofyan (51 tahun) lebih ringan daripada tuntutan jaksa hukuman mati. Sofyan ditangkap di rumahnya di Neusu, Banda Aceh, petugas menemukan bahan baku pembuatan sabu. Saat ditangkap, Sofyan masih berstatus sebagai narapidana dengan kasus kepemilikan narkoba. Ia ditahan di LP Lambaro. Aceh Besar dengan hukuman 19 tahun penjara. Sofyan keluar dari penjara 
karena dibantu kerabatnya yang juga sipir (Kompas, 22 Desember 2015).

BNN pada Rabu 27 Januari 2016 menangkap warga Negara Pakistan Muhammad Riaz alias Jane (45 tahun) yang diduga pengedar narkotika internasional di sebuah gudang mebel CV Jepara Raya Int'l di Desa Pekalongan, Rt.04/03 Kecamatan Batealit, Kabupaten Jepara Jawa Tengah. BNN juga mengamankan penyewa gudang Didi Triyono (40 tahun), penjaga gudang Sarkadi (71 tahun), pekerja gudang Karim (50 tahun). Ditemukan $300 \mathrm{~kg}$ narkoba jenis sabu yang dikemas dalam plastik berukuran 1,7-1,9 $\mathrm{kg}$ (tiap mesin genset) disimpan dalam 194 mesin generator set (genset) diesel merek Zhuoma yang didatangkan langsung dari Guangzhou China. Gudang itu disewa oleh CV Jepara Raya Internasional. Penyelundupan sabu dari Pakistan itu via Pelabuhan Tanjung Emas Semarang. Sindikat itu sudah diincar BNN sejak enam bulan. Jaringan Pakistan telah beroperasi di Indonesia sejak 2013 yang beroperasi di Jakarta, Semarang, hingga Jawa Timur (Kompas, 28 Januari 2016).

Di tengah tegasnya pemerintah menindak pengedar narkotika, Polres Aceh Timur bekerja sama dengan Badan Narkotika Nasional (BNN) menangkap Samsul pemilik dan pengedar narkoba dengan barang bukti siap jual seberat $75 \mathrm{~kg}$, senjata jenis FN 3 unit, peluru senjata FN 4 butir, senjata laras panjang jenis M16 1 unit, peluru senjata M 16120 butir dan uang sekitar Rp 49 juta di mobil minibus hitam milik Samsul di kawasan Desa Alue Bu, Kecamatan Peurlak Barat, Kabupaten Aceh Timur, Minggu 15 Februari 2015. Samsul diduga jaringan narkoba internasional (Kompas, 16 Februari 2015). Sistem keamanan di pesisir timur Aceh dari Kota Banda Aceh hingga Kabupaten Aceh Tamiang sekitar 400 km untuk mengantisipasi masuknya narkotika dan obat terlarang dari luar negeri masih lemah. Tahun 2015 awal, hanya ada empat kapal patroli milik polri, satu unit dari Mabes Polri dan tiga unit dari Polda Aceh. Banyaknya pelabuhan kecil yang bisa menjadi tempat bersandar kapal secara illegal di pesisir timur Aceh, terutama di Lhoksumawe, Aceh Utara, Aceh Timur, dan Aceh Tamiang yang selanjutnya narkoba didistribusikan ke wilayah Indonesia (Kompas, 27 Februari 2015). 
Imbas Konsistensi Hukuman Mati pada Hubungan Bilateral...

B. Daftar Narapidana Eksekusi Mati Bulan April 2015

Daftar narapidana tereksekusi mati hingga April 2015 sebagaimana tabel berikut.

\begin{tabular}{|c|c|c|c|}
\hline No & Nama & Kewarganegaraan & Kasus \\
\hline $\begin{array}{l}1 . \\
2 . \\
3 . \\
4 . \\
5 . \\
6 . \\
7 . \\
8 . \\
9 . \\
10 . \\
11 . \\
12 . \\
13 .\end{array}$ & $\begin{array}{l}\text { Myuran } \\
\text { Sukumaran } \\
\text { alias Mark } \\
\text { Andrew Chan } \\
\text { Syofial alias } \\
\text { Iyen bin } \\
\text { Azwar } \\
\text { Mary Jane } \\
\text { Fiesta Veloso } \\
\text { (ditunda) } \\
\text { Harus bin } \\
\text { Ajis } \\
\text { Sargawi alias } \\
\text { Ali bin Sanusi } \\
\text { Serge Areski } \\
\text { Atlaoul } \\
\text { (ditunda) } \\
\text { Martin } \\
\text { Anderson } \\
\text { alias Belo } \\
\text { Zainal Abidin } \\
\text { Raheem } \\
\text { Agbaje Salami } \\
\text { Rodrigo } \\
\text { Gularte } \\
\text { Silvester } \\
\text { Obiekwe } \\
\text { Nwolise } \\
\text { Okwudili } \\
\text { Oyatanze }\end{array}$ & $\begin{array}{l}\text { Australia } \\
\text { Australia } \\
\text { WNI } \\
\text { Filipina } \\
\text { WNI } \\
\text { WNI } \\
\text { Perancis } \\
\text { Ghana } \\
\text { WNI } \\
\text { Spanyol } \\
\text { Brasil } \\
\text { Nigeria } \\
\text { Nigeria }\end{array}$ & $\begin{array}{l}\text { Penyelundupan } \\
8,2 \text { kg heroin } \\
\text { Penyelundupan } \\
8,2 \text { kg heroin } \\
\text { Pembunuhan } \\
\text { berencana } \\
\text { Penyelundupan } \\
\text { 2,6 kg heroin } \\
\text { Pembunuhan } \\
\text { berencana } \\
\text { Pembunuhan } \\
\text { berencana } \\
\text { Penyelundupan } \\
\text { 250 kg sabu } \\
\text { Penyelundupan } \\
50 \text { kg heroin } \\
\text { Penemuan } 58 \mathrm{~kg} \\
\text { ganja } \\
\text { Penyelundupan } \\
5,8 \text { kg heroin } \\
\text { Penyelundupan } \\
6 \text { kg heroin } \\
\text { Penyelundupan } \\
1,2 \text { kg heroin } \\
\text { Penyelundupan } \\
1,5 \text { kg heroin }\end{array}$ \\
\hline
\end{tabular}

Dari 13 orang yang terdata tersebut yang akhirnya dieksekusi baru 8 orang, yakni Myuran Sukumaran dan Andrew Chan (Australia), Martin Anderson, Raheem A Salami, Sylvester Obiekwe, dan Okwudili Oyatanze (Nigeria), Rodrigo Gularte (Brasil), dan Zaenal Abidin (Palembang Indonesia). 
Serge Areski Atlaoul dari Perancis menggugat ke PTUN pada 24 April 2015 setelah PK-nya ditolak dengan grasi Presiden 23 April 2015 dan Mary Jane Fiesta Veloso asal Filipina ditunda eksekusi matinya karena adanya dugaan human trafficking. Gugatan Atlaoul atas grasi Presiden RI ditolak PTUN Jakarta, Senin 22 Juni 2015. Hakim Ketua PTUN Jakarta Ujang Abdullah menolak gugatan dengan dalih penolakan grasi bukan obyek sengketa TUN, grasi merupakan hak prerogratif presiden sehingga PTUN tidak berwenang mengadili gugatan atas grasi. Majelis menghukum paluku (Atlaoul) membayar perkara Rp 58.000 (Kompas, 23 Juni 2015). Adapun tim kuasa hukum keluarga terpidana mati kasus narkoba asal Brasil Rodrigo Gularte mencabut permohonan pengampunan yang telah diajukan ke PN Cilacap, sepekan sebelum eksekusi. Pencabutan dilakukan karena klien telah dieksekusi mati pada 29 April 2015 sehingga tak ada lagi yang dimintakan pengampunanyang diajukan sang pemohon, sepupu Rodrigo Gularte, Angelita Aparecida Muxfeldt diwakilkan pada tim kuasa hukumnya, Christina Windiarti saat sidang perdana yang digelar di ruang sidang Wijayakusuma PN Cilacap, Rabu 6 Mei 2015. Hakim tunggal Gede Putra Astawa menyatakan sidang tertutup untuk umum (Suara Merdeka, 7 Mei 2015). Hal yang berbeda, Rodrigo Gularte, menurut Jaksa Agung H.M Prasetyo meskipun ia didiagnosis mengalami gangguan kejiwaan tidak akan memengaruhi proses eksekusi. Berdasarkan UU Nomor 2/PNPS/1964, yang tidak boleh dieksekusi adalah perempuan hamil dan anak di bawah umur. Akan tetapi, Koordinator Riset Komisi untuk Orang Hilang dan Korban Tindak Kekerasan (Kontras) Puri Kencana Putri, mendesak pemerintah RI membatalkan eksekusi penderita gangguan jiwa (Kompas, 4 Maret 2015).

\section{Prosedur Pengajuan Peninjauan Kembali dan Pelaksanaan Hukuman Mati}

Kitab UU Hukum Acara Pidana (KUHAP) Pasal 67 mengatur permohonan peninjauan kembali (PK) bisa diajukan berdasarkan alasan (1) putusan didasarkan pada suatu kebohongan, (2) setelah perkara diputus ditemukan surat-surat bukti yang bersifat menentukan, (3) tidak dituntut lebih dari apa yang dituntut, (4) apabila antara pihak-pihak yang sama 
mengenai suatu soal yang sama, atas dasar yang sama oleh pengadilan yang sama atau sama tingkatnya, telah diberikan putusan yang bertentangan satu degan yang lain, (5) apabila dalam suatu putusan terdapat suatu kekhilafan hakim atau suatu kekeliruan yang nyata.

UU Nomor 2/PNPS/1964 Bab I Pasal 1 pelaksanaan hukuman mati dengan cara ditembak hingga mati. Sebelum dilakukan eksekusi, terdapat tata caranya. Pertama, Kapolda menentukan waktu dan tempat pelaksanaan pidana mati setelah mendengar nasehat jaksa yang bertanggung jawab mengeksekusi. Kedua, Kapolda bertanggung jawab atas keamanan dan ketertiban sewaktu pelaksanaan pidana mati dan menyediakan tenaga dan alat yang diperlukan untuk mengeksekusi. Ketiga, menunggu pelaksanaan pidana mati, terpidana ditahan dalam penjara atau di tempat lain yang khusus atas penunjukan jaksa. Keempat, selama 3×24 jam sebelum eksekusi, jaksa memberitahukan pada terpidana tentang rencana hukuman mati.. Kelima, apabila terpidana hendak mengemukakan sesuatu, maka keterangan atau pesannya bisa disampaikan kepada jaksa. Keenam, apabila terpidana hamil, eksekusi dapat dilaksanakan 40 hari setelah anaknya lahir. Ketujuh, pembela terpidana, atas permintaan sendiri atau atas permintaan terpidana dapat menghadiri pelaksanaan pidana mati. Kedelapan, Polda membentuk satu regu tembak dari Brimob terdiri 1 bintara, 12 tamtama, di bawah pimpinan 1 perwira. Kesembilan, terpidana dibawa ke tempat eksekusi dengan pengawalan polisi yang cukup. Kesepuluh, jika diminta, terpidana dapat disertai seorang perawat rohani. Kesebelas, setiba di tempat eksekusi, komandan pengawal menutup mata terpidana dengan sehelai kain, kecuali terpidana tak menghendaki. Kedua belas, terpidana dapat menjalani pidana dengan berdiri, duduk, atau berlutut. Ketiga belas, jika dipandang perlu, jaksa eksekutor dapat memerintahkan supaya terpidana diikat tangan dan kakinya atau diikat di sandaran yang khusus dibuat untuk eksekusi. Keempat belas, setelah terpidana siap ditembak, regu penembak dengan senjata sudah terisi (peluru) menuju ke tempat yang ditentukan oleh jaksa. Kelima belas, jarak antara titik di mana terpidana berada dan tempat regu penembak tak boleh melebihi $10 \mathrm{~m}$ dan tak boleh kurang dari $5 \mathrm{~m}$. Keenam belas, 
komandan regu penembak dengan menggunakan pedang memberikan isyarat dan memerintahkan anggotanya membidik jantung terpidana. Ketujuh belas, bila setelah penembakan, terpidana masih memperlihatkan tanda bahwa ia belum mati, maka komandan regu segera memerintahkan kepada bintara regu tembak untuk melepaskan tembakan pengakhir dengan menekankan ujung laras senjatanya pada kepala terpidana tepat di atas telinga. Kedelapan belas, penguburan diserahkan kepada keluarganya atau sahabat terpidana, kecuali jika berdasarkan kepentingan umum jaksa yang bertanggung jawab memutuskan lain.

\section{Hukuman Mati dalam Islam}

Pada surat Al-Baqarah ayat 178 dijelaskan bahwa, yang artinya; "Hai orang yang beriman, diwajibkan atas kamu hukuman mati (qishaash) berkenaan dengan pembunuh". Dalam hadis yang diriwayatkan Bukhori dan Muslim "Tidak halal darah seorang muslim (untuk dibunuh) kecuali disebabkan oleh tiga hal, membunuh orang, janda/duda yang berzina, dan orang yang murtad". Ayat dan hadits tersebut dalam pelaksanaannya terdapat aturan main yang dikaji dalam fikih jinayat/jarimah (hukum pidana Islam) yakni perbuatan yang dilarang oleh syarak karena merugikan jiwa, harta, atau lainnya (Ridwan, 2008:15). Adanya hukum sebagai upaya negara mempertahankan hukum, ketertiban, dan keamanan dengan wewenang dan kekuasaan untuk menjatuhkan hukuman pidana yang mempengaruhi kehidupan, kebebasan, dan pemilikan individu (An-Na'im, 1990:193). Tujuan adanya hukum karena pergaulan masyarakat ada kepentingan dalam pemenuhan kebutuhan. Pemenuhan ini tak menutup kemungkinan terjadi gesekan atau benturan sehingga diperlukan hukum (Murdiana, 2015:22). Hukum Pidana Islam maupun konvensional terimplementasikan dalam asas legalitas (al-Quran: al-Baqarah:59, al-Anfal: 38, al-Isra':15, dan al-Qashash:59) dan asas tak berlaku surut (nonretroaktif) (Jahar, dkk, 2013:124). Hukum Islam dapat diperoleh melalui ketentuan nash (al-Quran dan hadis) dan ijtihad (qiyas, istishlah, istihsan, istish-hab, 'urf/pengukuhan adat) (Basyir, 1996:127).

Adapun pengedar dan pemasok narkoba dapat ditafsiri sebagai pembunuhan secara masif bagi penggunanya karena 
bahaya narkoba. Menurut Nurdin, efek spesifik mental zat psikoaktif terhadap susunan saraf pusat akibat perangsangan (agonis) atau penghambatan (antagonis) pada sistem neurotransmitter yang berperan pada transmisi interneuronal yang mengatur fungsi kognitif, afektif, dan psikomotor. Akibatnya merusak fungsi kognitif (psikolitik) yang tak mampu membedakan antara realita dengan khayalan (autism), mengubah kepribadian adaptif (psikopatisasi), menimbulkan halusinasi (halusinogenisasi), meningkatnya ekspresi emosi (psikomimetik), hilangnya rasa takut, kuatir, malu, dan menyesal (disinhibisi) (Nurdin, 2007:175).

\section{E. Eksekusi Warga Asing di Indonesia yang Kontroversi dalam Kasus Narkoba}

Gugatan atas penolakan grasi vonis mati warga Negara Australia a.n Andrew Chan dan Myuran Sukumaran terhadap Keputusan Presiden Jokowi Nomor 32/G/2014 30 Desember 2014 tidak diterima Pengadilan Tata Usaha Negara (PTUN) Jakarta. Hal ini dinyatakan Ketua PTUN Jakarta dalam sidang terbuka di PTUN Jakarta Selasa 24 Februari 2015 yang tertuang dalam gugatan Nomor 30/G/PTUN-JKT. Kedua terpidana dibebani membayar Rp 131 ribu. Kuasa hukum terpidana Todung Mulya Lubis melakukan banding atas penolakan PTUN Jakarta (Suara Merdeka, 25 Februari 2015). Jaksa Agung HM Prasetyo menyatakan, setelah seorang terpidana mengajukan grasi, seharusnya mereka tak bisa lagi menempuh upaya hukum lain. Logikanya, jika mengajukan grasi, orang itu mengaku salah, menerima putusan, dan meminta maaf. Terpidana mati yang mengajukan upaya hukum untuk meringankan hukumannya melalui peninjauan kembali (PK) yakni Serge Areski Atloui, warga Perancis yang ditangkap pada November 2005 sidang PK-nya dijadwal 11 Maret 2015 di Pengadilan Negeri Tangerang (Kompas, 27 Februari 2015).

Permohonan grasi terpidana mati kasus narkoba asal Australia yang dikenal 'Bali Nine', Andrew Chan ditolak yang kedua oleh Presiden Jokowi pada 17 Januari 2015 tertuang dalam Kepres Nomor 9/G tahun 2015. Sebelumnya, terpidana 'Bali Nine', Myuran Sukumaran asal Australia sudah ditolak permohonan grasinya pada 30 Desember 2014. Pengadilan Tata Usaha Negara (PTUN) Jakarta Timur menolak permohonan 
gugatan perlawanan dua terpidana mati asal Australia. Gugatan keduanya diajukan pada 24 Februari 2015 atas Keppres Nomor 9/G tanggal 17 Januari 2015 a.n Andrew Chan tidak bisa diadili oleh PTUN. Begitu pula Keppres Nomor 32/G tanggal 17 Januari 2015 a.n Myuran Sukumaran ditolak PTUN. Upaya keduanya di PTUN merupakan jalan terakhir untuk menghindari hukuman mati. Dua terpidana dikenakan biaya perkara, pada Andrew sebesar Rp 49.500 dan Myuran Rp 50.500 (Koran Sindo, 7 April 2015).

Mary Jane Fiesta Veloso (Filipina), Serge Areski Atlaoul (Perancis), dan Myuran Sukumaran alias Mark (Australia). Adapun terpidana mati yang ditolak grasinya pada 9 Januari 2015, yaitu Raheem Agbaje Salami (Spanyol), Martin Anderson alis Belo (Ghana), Rodrigo Gularte (Brasil), Zainal Abidin (WNI). Silvester Obiekwe Nwolise dan Okwudili Oyatanze, kedua warga Nigeria ini grasinya ditolak Presiden Jokowi pada 5 Februari 2015. Adapun Mary Jane Fiesta Veloso (29 tahun) asal Filipina dalam Kepres Nomor 31/G/2014 bahwa permohonan grasinya ditolak Presiden RI. Mary Jane mengajukan PK ke MK. Sesuai Keputusan MA dalam Surat Edaran Nomor 7 Tahun 2014 bahwa permohonan PK hanya dapat diajukan sekali. Mary Jane pada 24 April 2010 ditangkap petugas Bandara Adisutjipto Yogyakarta, karena perempuan tersebut membawa heroin seberat 2,6 kg April 2010. Jane divonis mati oleh PN Sleman yang diketuai Dahlan karena terbukti melanggar Pasal 114 ayat 2 UU Nomor 35 Tahun 2009 tentang Narkotika. Hukuman itu lebih berat dari tuntutan jaksa yang mengajukan vonis seumur hidup (Suara Merdeka, 24 Februari 2015). Presiden Filipina Rodrigo Dulerte mempersilakan Presiden Jokowi mengeksekusi mati terhadap terpidana mati penyelundup narkoba asal Filipina, Mary Jane Veloso.

Senin 27 April 2015 Majelis Hakim MA yang dipimpim Hakim Agung Surya Jaya dengan anggota Desnayeti dan Syarifuddin secara bulat tanpa adanya dissenting opinion menolak PK yang diajukan Zainal Abidin karena tidak adanya novum baru (kekhilafan hakim, dan kekeliruan dalam keputusan berikutnya). Zainal Abidin bin Mgs Mahmud Badaruddin mengajukan PK dan pada 13 Februari, ia termasuk daftar calon narapidana dieksekusi yang diumumkan 
Kejaksaan Agung pada 13 Februari 2015. Sebelumnya pada 2 Mei 2005 ia mengajukan PK. Ternyata PK tak terkirimkan ke MA hingga 2015. Hal ini diketahui setelah pengacaranya Ade Yuliawan mengecek ke MA setelah adanya penolakan grasi oleh Presiden Jokowi 2 Januari 2015. Pengadilan Negeri Palembang baru memproses kembali PK Zainal dengan mendaftar ke MA pada 19 Januari 2015. Zaenal tidak bisa melaporkan kecerobohan ini karena tahun 2005 belum ada Komisi Yudisial. Pada 5 Maret 2015 penasehat hukumnya Ade Yuliawan berkunjung ke LP Pasir Putih Nusakambangan Cilacap, Zainal menulis surat terbuka "Saya tidak terima atas perlakuan hukum yang tidak adil dan tidak ada kepastian hukum bagi rakyat kecil seperti saya ini yang sejak awal saya hanya dibantu lembaga bantuan hukum. Apabila pelaksanaan eksekusi mati ini tetap dipaksakan sebelum saya menerima amar putusan MK, maka arwah saya tidak tenang, gentayangan, dan akan menuntut balas, termasuk kepada isteri, anak, dan keturunannya seluruh perangkat hukum yang terlibat.

Kasus yang menimpa Zainal berawal dari penggerebekan polisi di rumah keluarga besar Zainal di Jalan Ki Gede Ing Suro, No 24, Lr Tangga Tanah, Rt 001 Rw.001, kelurahan Ilir, Kecamatan Ilir Barat II, Palembang pada 21 Desember 2001 subuh. Polisi menyita barang bukti berupa tiga karung plastik berisi ganja seberat 58,7 kg. Zainal ditangkap bersama Kasyah bin Karta (isterinya) dan Aldo (teman Zainal asal Aceh). Di PN Kelas 1 A Pelembang, Zainal divonis 18 tahun penjara dan denda Rp 5 juta subsider enam bulan kurungan, Kasyah 3 tahun penjara, dan Aldo 20 tahun penjara. Putusan PN Palembang pada 27 November 2001 memperberat Zainal menjadi pidana mati. Pada 28 Mei 2002 kasasinya ditolak (Kompas, 23 April 2015).

Berdasarkan UU Nomor 2/PNPS/1964 tentang Tata Cara Pelaksanaan Pidana Mati, bila kejahatan dilakukan lebih dari 1 orang, maka eksekusi dilakukan bersamaan dengan terpidana mati lainnya. Hingga Januari 2015 terdapat 64 terpidana mati yang akan dieksekusi Kejagung (Suara Merdeka, 23 Januari 2015). 'Bali Nine' merupakan Sembilan warga Australia yang ditangkap pada 17 April 2005 di Bali yang menyelundupkan heroin seberat $8,202 \mathrm{~kg}$ dari Australia melalui bandara Ngurah 
Rai Bali. Empat anggota Bali Nine tertangkap tangan membawa heroin di Bandara Ngurah Rai dan lima lainnya ditangkap di kawasan Kuta Bali. Kesembilannya adalah Andrew Chan, Myuran Sukumaran, Si Yi Chen, Michael Czugai, Renae Lawrence, Tach Duc Thanh Nguyen, Matthew Norman, Scott Rush, dan Martin Stephens. Myuran dan Andrew ditangkap di Bandar Ngurah Rai dan Andrew sebagai otak penyelundupan. Myuran dan Andre ditahan di LP Krobokan Bali. Pengadilan Negeri Denpasar memvonis Lawrence, Czugai, Stephen, dan Rush dengan hukuman penjara seumur hidup, sedangkan Sukumaran dan Chan dihukum mati yang permohonan grasinya ditolak presiden pada Kamis 22 Januari 2015.

Menteri Luar Negeri Australia Julie Bishop Jumat 13 Februari 2015 mengharap agar Indonesia tak lupa bahwa Australia banyak membantu Indonesia memberantas narkoba, program rehabilitasi pecandu narkoba, dan pengurangan dampak narkoba di Indonesia sehingga mengharap Indonesia tidak menghukum mati dua warganya, Myuran Sukamaran dan Andrew Chan. Kedua terpidana divonis hukuman mati dan telah mendekam di penjara Kerobokan Bali selama sembilan tahun akan dipindah ke LP Nusakambangan untuk dieksekusi. Australia menghapus hukuman mati sejak 1967, ada 114 orang yang sempat dihukum mati di Australia sebelum 1967 (Kompas, 14 Februari 2015). Wajarlah bila Kedubes RI di Canberra Australia mengirimkan surat edaran bagi WNI di Australia agar meningkatkan kewaspadaan dan mencermati perkembangan situasi dengan membawa selalu tanda pengenal yang masih berlaku seperti paspor, kartu mahasiswa, bukti identitas lainnya, meningkatkan komunikasi antarwarga, menghindari ikut campur tangan dalam masalah politik Australia, dan mengindahkan peraturan setempat (Suara Merdeka, 14 Februari 2015).

Hubungan RI dengan Australia menghangat seiring rencana eksekusi mati Kejaksaan Agung terhadap dua warga Australia yakni Myuran Sukumaran dan Andrew Chan karena tertangkap mengedarkan narkoba di Indonesia. Ancaman Australia dinyatakan oleh Menlu Australia Julie Bishop Jumat 13 Februari 2015 yang akan mempertimbangkan untuk mengurungkan perjalanan pariwisata ke Indonesia bagi warga Australia bila pemerintah RI tetap mengeksekusinya. Sekretaris 
Kabinet (saat itu) Andi Widjajanto menyatakan, Presiden Jokowi tidak akan mengubah keputusan hukuman yang telah ditetapkan kepada para terpidana mati kasus Bali Nine. Penolakan grasi sejalan dengan program pemerintah Indonesia untuk menyatakan perang terhadap narkoba. Sekjen PBB Ban Ki-Moon merespon dengan menghimbau Indonesia pada Jumat 13 Februari 2015 untuk menghentikan eksekusi hukuman mati bagi narapidana untuk kejahatan narkoba. PBB menentang hukuman mati dalam segala kondisi. Perdana Menteri Australia (saat itu) Tony Abbott melayangkan surat permohonan pada Presiden Jokowi agar mengindahkan seruan Pemerintah Australia untuk menghentikan eksekusi mati. Jutaan warga Australia marah dengan eksekusi itu (Republika, 15 Februari 2105). Surat tersebut bukan merupakan langkah terakhir Australia untuk menghentikan hukuman mati. Perdana Menteri Australia Tony Abbott melontarkan pernyataan kekesalan pada Indonesia setelah upayanya agar pemerintahan Jokowi menghentikan hukuman mati pada warganya dengan mengungkit pemberian bantuan tatkala musibah tsunami di Aceh sebesar Rp 13 triliun. Menlu Australia Julie Bishop Jumat 20 Februari 2015 melakukan komunikasi langsung dengan Wapres Jusuf Kalla untuk meluruskan pernyataan Tony Abbott. Pernyataan Abbot bukan menekan Indonesia dalam menghukum pengedar narkoba. Tetapi, Australia ada ketika Indonesia menghadapi musibah. Australia tetap ingin bekerja sama dalam mengatasi masalah narkoba dan sindikatnya. Pernyataan ini agar menurunkan tensi kerenggangan Indonesia-Australia. Menurut Wapres Jusuf Kalla, proses hukum tetap berjalan. Warga Australia pun mengecam pernyataan PM Abbot (Republika, 22 Februari 2015). Adapun respon Wapres Jusuf Kalla terhadap pernyataan PM Australia Toni Abbot, musibah tsunami Aceh 2004 ada 56 negara yang membantu di antaranya Australia. Bila Australia menganggapnya bukan bantuan kemanusiaan, Indonesia siap mengembalikan bantuannya. Wapres pun menganggap wajar bila rakyat Aceh dan lainnya geram dengan mengumpulkan koin untuk diberikan pada Australia, meskipun pernyataan Abbot diluruskan oleh pejabat Australia (Suara Merdeka, 24 Februari 2015). Respon serupa dilakukan Bambang Saptono pada Jumat 6 Maret 2015 mengirim dua peti jenazah untuk dua 
narapidana Australia. Akan tetapi, peti dikembalikan Kedubes Australia dengan alamat pengiriman di Kantor Besar Surakarta yang ditujukan pada Bambang Saptono. Bambang dihubungi sentra layanan paket kantor pos bahwa pukul 10.00 Sabtu pagi ada kiriman peti dari Kedubes Australia di Jakarta. Peti tertulis diterima satpam Kedubes Australia pada 9 Maret 2015 dan peti ditolak. Akhirnya Bambang membakar pengembalian peti tersebut di Bundaran Gladag Jalan Slamet Riyadi Solo Satu 14 Maret 2015 (Suara Merdeka, 15 Maret 2015).

Menjelang hari eksekusi warga Australia, Andrew Chan dan Myuran Sukumaran, gerbang kantor Konsulat Jenderal RI di Sydney, Australia, Senin malam pukul 05.40 waktu setempat 28 Februari 2015 dilempari 8-10 balon berisi cairan merah (Kompas, 4 Maret 2015). Menteri Luar Negeri Australia Julie Bishop Selasa 3 Maret 2015 menelepon Menlu RI Retno Marsudi menjelang eksekusi mati warga negaranya menawarkan barter narapidana (swap prisoner) dengan tiga terpidana asal Indonesia di Australia kasus narkoba, yakni Kristito Mandagi, Saud Siregar, dan Ismunandar. Ketiganya hendak menyelundupkan 252,3 kg heroin senilai Rp 4-6 triliun dengan kapal dari Indonesia ke Australia pada 1998 yang ditangkap di Port Macquarie Australia. Kristito divonis hukuman seumur hidup tanpa masa pembebasan bersyarat 25 tahun. Atas pengajuan bandingnya, masa bandingnya dikurangi enam tahun menjadi hukuman 19 tahun (tidak seumur hidup). Kristito berhak mengajukan pembebasan bersyarat pada Oktober 2017. Saud dan Ismunandar divonis 20 tahun penjara dan berhak mengajukan pembebasan bersyarat pada 2018. Hal ini ditolak Presiden Jokowi karena tak ada dasar hukum barter. Menurut Wapres Jusuf Kalla, permohonan Australia bukan ditolak, tapi tak bisa (dipenuhi) karena sistem hukum kita tak mengenalnya (barter) (Kompas, 6 Maret 2015). Data Direktur Perlindungan WNI dan Badan Hukum Indonesia (PWNIBHI) ada sekitar 228 WNI terancam hukuman mati di luar negeri yang 60 persen di antaranya kasus narkoba.

Berbagai cara ditempuh Australia untuk membatalkan eksekusi mati warganya di Indonesia. Upaya yang dilakukan yakni anggota Senat Australia Nick Xenophon bersama Imam Masjid Afghan, Adelaide, Australia, Syekh Kafrawi Abdurahman Hamzah, Selasa 10 Maret 2015 mendatangi 
Pengurus Besar NU (PBNU) diterima Ketua Syuriah K.H Masdar F Mas'udi, Sekjen Marsyudi Syuhud, Bendara Umum Bina Suhendra, Ketua Mohammad Maksoem Mahfudz, Slamet Efendi Yusuf, Iqbal Sullam, dan Kacung Marijan. Kedatangan Senat dan Imam Masjid Australia untuk meminta dukungan atas keinginan pemerintahnya menunda eksekusi, bukan membatalkan untuk pembelajaran warga Australia bahwa narkoba membahayakan. Marsudi Syuhud menyatakan, tidak semua hukuman mati didukung NU. Ketika pemerintah Mesir akan mengeksekusi mati tahanan politik, NU mengirim surat ke PBB agar menghentikannya. Namun, jika narkoba NU mendukung hukuman mati karena akibat narkoba membunuh 50 warga Indonesia setiap hari. Anggota Dewan Pertimbangan Presiden (Wantimpres) Hasyim Muzadi mendesak Presiden Jokowi tak ragu-ragu mengeksekusi terpidana mati karena narkoba (Suara Merdeka, 11 Maret 2015). Menteri Luar Negeri Australia Julie Bishop berupaya membebaskan warganya dari hukuman mati menjadi hukuman seumur hidup dan menanggung biaya hidup kedua narapidananya. Surat tersebut ditujukan pada Menlu RI Retno Marsudi dengan surat yang berisi penolakan (Tribun Jateng, 13 Maret 2015).

Fakta lain, rencana pengiriman duta seni Boyolali ke Australia dan Selandia Baru dibatalkan Australia. Menurut Kepala Dinas Pendidikan, Pemuda, dan Olahraga Boyolali, Abdul Rahman, pengiriman Juli 2015 dialihkan ke Jepang, Tiongkok, dan Korea. Hal ini akibat hubungan yang kurang baik antara Indonesia dengan Australia (Suara Merdeka.com, 12 April 2015). Julian Oldmeadow dosen mata kuliah psikologi di Universitas Swinburne Australia melarang mahasiswa asal Indonesia untuk mengikuti kuliahnya. Hal ini terjadi karena ia kesal dengan langkah pemerintah Indonesia mengeksekusi dua gembong narkoba asal Australia, meski tidak ada mahasiswa asal Indonesia yang kuliah dengannya. Pelarangan Julian tidak ditindaklanjuti pihak kampus karena kampus menyambut baik semua mahasiswa dari mana pun (Suara Merdeka, 3 Mei 2015).

Menjelang dieksekusinya Bali Nine, mencuat pemberitaan di media Australia adanya suap dari hakim yang mengadili penanganan perkara Bali Nine dengan terpidana Andrew Chan dan Myuran Sukumaran senilai Rp 1 miliar agar para terdakwa dihukum di bawah 20 tahun penjara. Komisi 
Yudisial telah menerima laporan tersebut dari pengacara Andrew dan Myuran, Todung Mulya Lubis dan Komisi Yudisial (KY) memrosesnya. Komisioner KY (saat itu) Taufiqurahman Syahuri menjelaskan bahwa laporan pengacara tersebut tidak menghalang-halangi proses eksekusi karena pemeriksaam KY pada hakim yang diduga menyeleweng tersebut dalam hal pelanggaran etik yang tidak memengaruhi putusan hakim (Kompas, 28 April 2015). Akhirnya tetap dieksekusi kedua Bali Nine pada Rabu 29 April 2015 dini hari di Nusa Kambangan, Cilacap.

Menurut Guru Besar Hukum Internasional Universitas Indonesia Hikmahanto Juwana, Indonesia harus teguh melaksanakan hukuman mati. Permintaan Ban Ki-Moon dinilai cenderung mengintervensi dan terkesan membela negara maju. Ki-Moon dinilai diskriminatif, ketika Ruwiyati divonis pancung di Arab Saudi, Ki-Moon tak bersuara. Lantas bagaimana dengan negara yang masih memberlakukan hukuman mati, seperti Malaysia, Singapura, dan Amerika. Sikap Ko-Moon diduga atas desakan Australia. Jaksa Agung HM Prasetyo mengirim surat pemindahan Myuran Sukumaran dan Andrew Chan Minggu 15 Februari 2015 pada Kejati Bali yang ditembuskan pada Kejari Denpasar Bali. Dalam surat dinyatakan terdapat 20 jaksa yang ditunjuk mengawal Chan dan Sukumaran (Suara Merdeka, 16 Februari 2015). Setiap negara mempunyai kewajiban melindungi warga negaranya ketika berada di luar negeri. Dalam hukum internasional disebut diplomatic protection. Kewajiban itu untuk melindungi warganya bukan untuk membela atau membenarkan kejahatan warganya. Kewajiban itu pula tidak boleh sampai derajat mengintervensi kedaulatan negara lain (Juwana, 2015:7). Majelis Ulama Indonesia (MUI) mendukung penuh kebijakan pemerintah Indonesia yang tetap mengeksekusi mati terpidana narkoba. Hal ini menurut Wakil Ketua MUI (saat itu) M. Ma'ruf Amin sesuai fatwa MUI bahwa memproduksi, mengedarkan, dan mengonsumsi narkoba adalah haram dan harus dihukum berat (Suara Merdeka, 4 Maret 2015).

Imbas dieksekusinya Andrew Chan dan Myuran Sukumaran Pemerintah Australia memangkas dana bantuan kepada Indonesia dari AUD 542,5 juta (Rp 5,8 triliun) menjadi AUD 323 juta (sekitar Rp 3,4 triliun). Hal ini terungkap saat 
Menkeu Australia Joe Hockey menyampaikan RAPBN 20152016 di depan parlemen Selasa 12 Mei 2015. Joe membantah pemotongan berkait dengan eksekusi mati warga Australia oleh Indonesia. Menurut Juru Bicara Kemenlu RI Arrmanatha, pemotongan bagi Negara yang sanggup mengalokasikan dana bantuan dan potensi ekonominya tinggi. Bahkan Negara di kawasan Afrika menjadi korban pemotongan dana hingga 70 persen (Jawa Pos, 14 Mei 2015).

\section{F. Sikap Mendingin Australia pada Indonesia Pasca- eksekusi}

Setelah dieksekusinya Bali Nine, PM Australia Abbot melalui Menlunya Julie Bishop via ABC News Jumat 1 Mei 2015 mengabarkan, pemerintah Australia memandang ke depan melewati peristiwa eksekusi (Suara Merdeka, 2 Mei 2015). Ketegangan hubungan diplomatik antara Indonesia dengan Australia makin mereda dengan dilakukannya kerja sama kedua negara di bidang kontraterorisme dan konektivitas maritim pada Senin 21 Desember 2015 di Sydney Australia. Hal ini ditandai dengan pertemuan dua Menlu yakni Menlu RI Retno LP Marsudi dan Menlu Australia Julie Bishop. Kedua negara bersepakat memerangi terorisme internasional dalam MOU antara Ketua BNPT Saud Usman Nasution dengan Sekjen Departemen Luar Negeri Australia Peter Varghese (Kompas, 22 Desember 2015).

Imbas divonis mati dan tidak adanya pengampunan bagi pengedar narkoba di Indonesia bagi WNI atau WNA, negara di mana terpidana mati sebagai warga negaranya, ia melakukan upaya 'perlawanan'. Perlawanan dilakukan oleh Brasil yang warga negaranya divonis mati, yakni Marco Archer Cardoso pada Januari 2015 dan rencana dieksekusinya Rodrigo Gularte. Oktober 2014, terpilihnya Dubes RI untuk Brasil, Toto Riyanto. Riyanto, mantan Direktur Eksekutif DPP Partai Demokrat, setelah menetap di Brasil selama 3 bulan, ia diundang Brasil dalam upacara khusus di Istana Presiden Brasil pada Jumat 20 Februari 2015 beserta lima dubes negara lain. Akan tetapi, undangan tiba-tiba dibatalkan tatkala Riyanto sudah di Istana Negara Brasil. Presiden Brasil Dilma Rousseff menolak surat kepercayaan Dubes RI untuk Brasil. Hal ini direspon oleh pemerintah RI pada hari Jumat 20 Februari 2015 pukul 22.00. 
Riyanto ditarik kembali ke Jakarta seketika hingga jadwal baru penyerahan credential dipastikan pemerintah Brasil. Hal ini sebagai bentuk protes pemerintahan Jokowi (Republika, 22 Februari 2015). Sikap Presiden Jokowi merespon Brasil bahwa Brasil melanggar tata karma dalam hubungan diplomatik. Menurut Direktur Eksekutif Humn Rights Working Group Rafendi Djamin, Brasil menggunakan langkah diplomasi keras karena proses peradilan di Indonesia belum sepenuhnya menjalankan prinsip peradilan yang benar-benar adil (Kompas, 24 Februari 2015).

DPR RI sepakat ketegasan Presiden Jokowi dan perlu mengevaluasi kerja sama bidang pertahanan. Alokasi anggaran tahun 2009-2014 pemerintah RI memesan pesawat Super Tocano dari Brasil yang akan digunakan untuk mengawasi garis pantai dan sistem peluncur roket multilaras (multi launcher rocket system/MLRS). Di bidang perdagangan, Brazil berupaya mengekspor daging sapi ke Indonesia (Kompas, 23 Februari 2015). Ketua Umum PB NU Said Aqil Siroj mendukung sikap pemerintah RI yang menolak permohonan grasi pada terpidana mati kasus narkoba. Dukungan ini mempertimbangkan aspek kemanusiaan dari jutaan orang yang menjadi korban kejahatan narkoba (Kompas, 27 Februari 2015).

\section{G. Reaksi non-Kontra Negara yang Warga Negaranya Dihukum Mati}

Duta Besar Perancis untuk RI Corinne Breuze mengatakan, pihaknya menghargai penegakan hukum di Indonesia dan tidak akan menuntut apa pun. Kendati demikian, ia tetap berharap pengajuan PK dari warganya bisa membuahkan hasil berupa keringanan hukuman (Kompas, 27 Februari 2015). Menlu Perancis Laurent Fabius pada 9 April 2015 memanggil Dubes RI untuk Perancis di Perancis perihal eksekusi Serge Areski Atlaoul. Serge mengajukan gugatan ke PTUN sehingga tidak dieksekusi pada 29 April 2015. Andrew Chan Senin 27 April 2015 selaku narapidana (sebelum dieksekusi 29 April 2015) menikah dengan Febiyanti Herewila di LP Nusakambangan. Hal itu merupakan permintaan terakhir Chan sebelum dieksekusi mati. 


\section{H. Eksekusi Mati Narapidana Narkoba Tahap Ketiga Era Presiden Jokowi}

Pelaksanaan eksekusi tahap ketiga dilaksanakan jaksa eksekutor Kejaksaan Agung terhadap 4 terpidana pada Jumat 29 Juli 2016 pukul 00.45 Wib di LP Nusakambangan, Cilacap, Jawa Tengah. Rencana awal, yang dieksekusi ada 14 narapidana. Hal ini dibuktikan dengan masuknya 17 mobil ambulance dari puskesmas di Cilacap dan 14 mobil tersebut membawa peti jenazah masuk di LP Nusakambangan menjelang hari eksekusi melalui kapal feri Dermaga Wijayapura, Cilacap yang dikawal brimob bersenjata laras panjang.

\begin{tabular}{|c|c|c|c|}
\hline No & Nama & Asal & Keterangan \\
\hline $\begin{array}{l}1 . \\
2 . \\
3 . \\
4 .\end{array}$ & $\begin{array}{l}\text { Michael Titus Igweh } \\
\text { Humprey Jefferson } \\
\text { Seck Osmane } \\
\text { Fredi Budiman }\end{array}$ & $\begin{array}{l}\text { Nigeria } \\
\text { Nigeria } \\
\text { Senegal } \\
\text { WNI }\end{array}$ & $\begin{array}{l}\text { Vonis PN Jaksel } \\
21 / 7 / 2004, \\
\text { kepemilikan } \\
\text { heroin }\end{array}$ \\
\hline
\end{tabular}

Keempatnya tersebut menurut Jampidum Kejagung dianggap menyalahgunakan narkoba secara massif www.bbc.com 29 Juli 2016). Adapun ke-10 narapidana yang ditunda eksekusi 29 Juli 2016 menurut Jaksa Agung Muda Pidana Umum (Jampidum) Noor Rachmad sebagai penanggung jawab lapangan melaporkan setelah pembahasan bersama unsur di daerah, Kapolda Jateng, dan pejabat konsulat Kementerian Luar Negeri maka hanya empat yang dieksekusi. Ke-10 narapidana akan dikaji ulang aspek hukum dan nonhukum untuk menghindari kesalahan.

Humprey Jefferson (Jeff) pria kelahiran 31 Desember 1972 ditangkap pada Agustus 2003 di Jakarta. Polisi menemukan $1,7 \mathrm{~kg}$ heroin di dalam restoran miliknya. April 2004 PN Jakarta Pusat memutus Jeff dipidana mati. November 2004 pengajuan banding Jeff ditolak MA. Seck Osmane divonis hukuman mati pada 2004 atas dakwaan menyimpan dan mengedarkan 2,4 kg heroin di kosnya di Lebak Bulus Jakarta 
Selatan tahun 2003. PK Seck ditolak MA. Michel Titus Igweh pada 2002 tertangkap memiliki 5,8 kg heroin. Tahun 2003 divonis mati. Tahun 2011 PK pertamanya ditolak, PK kedua tahun 2016 juga ditolak. Freddy Budiman divonis mati karena menyelundupkan 1,4 juta pil ekstasi dari China tahun 2011. Pada 20 Juli 2016 PK Freddy ditolak MA.

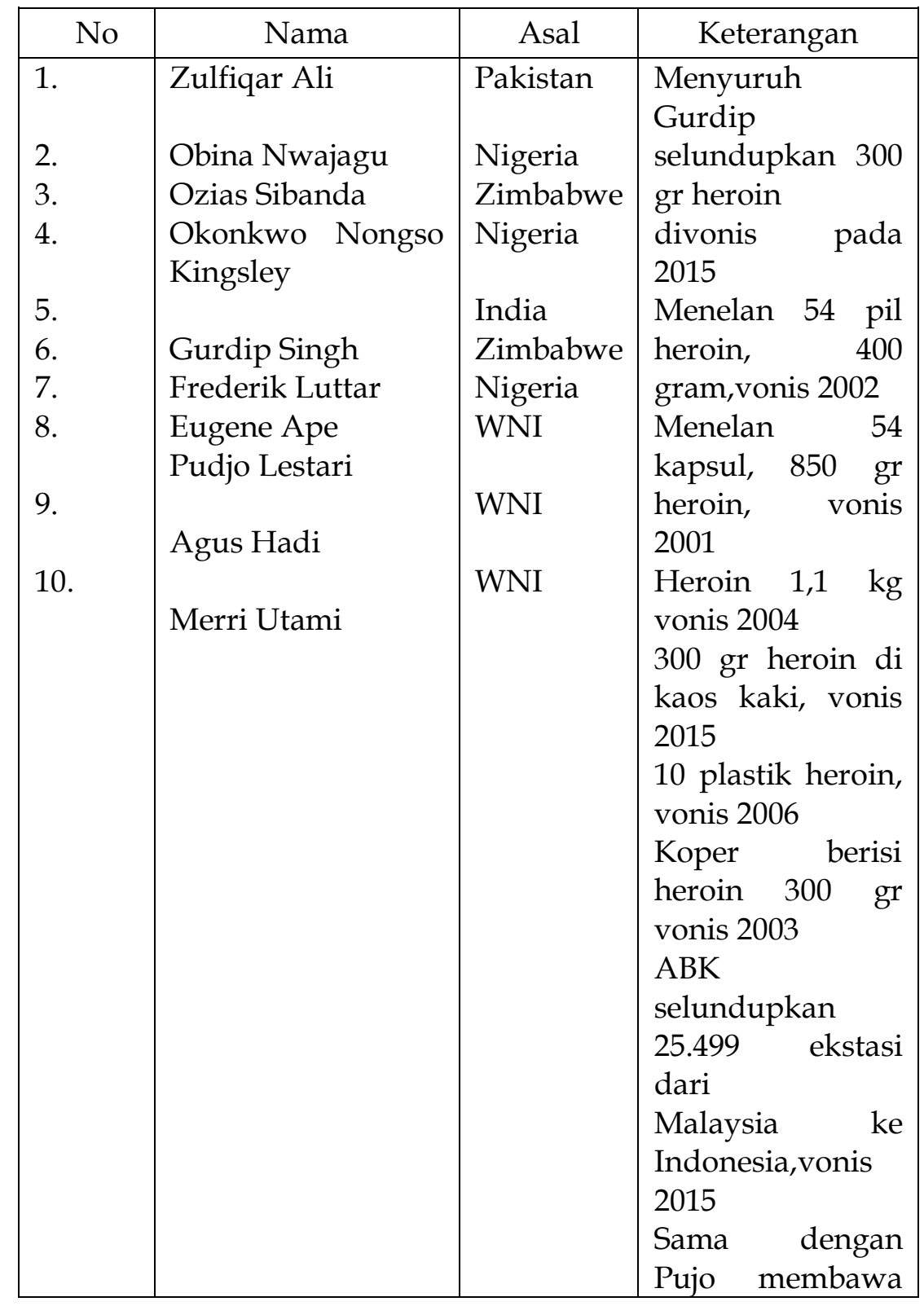


Imbas Konsistensi Hukuman Mati pada Hubungan Bilateral...

\begin{tabular}{|l|l|l|}
\hline & & $\begin{array}{l}\text { tas berisi } 1,1 \mathrm{~kg} \\
\text { heroin, vonis } \\
2002\end{array}$ \\
\hline
\end{tabular}

Zulfiqar Ali pada Kamis tengah malam 28 Juli 2016 telah mengenakan baju putih untuk menjalani eksekusi mati dini hari 29 Juli 2016. Sekitar lima menit sebelum eksekusi, pengacara Zulfiqar, Saut Edward Rajagukguk yang berada di lokasi eksekusi diberi tahu penundaan eksekusi Zulfiqar. Tidak bedanya pada 28 April 2015 tatkala Mary Jane yang sudah mengenakan baju putih untuk dieksekusi, batal dibawa ke lokasi eksekusi dengan dalih pemerintah RI menghargai proses hukum yang sedang berjalan di Filipina terkait kasus perdagangan manusia yang menimpa Mary Jane. Merri Utami, Pudjo Lestari, Agus Hadi, dan Humprey Jefferson Ejike mengajukan grasi pada Presiden Jokowi, meski hanya Ejike yang tetap dieksekusi mati 29 Juli 2016. Amnesty International mencatat terjadi proses peradilan yang cacat. Zulfiqar tak mendapat bantuan hukum yang memadai sejak ditangkap. Raheem Agbaje Salami tak mendapat penerjemah dan tak mendapatkan bantuan hukum yang memadai karena kemampuan finansial yang tak memadai (Kompas, 30 Juli 2016).

\section{Pro-Kontra Eksekusi Mati}

Pro-kontra hukuman mati masing-masing memiliki argumen hukum. Bagi yang kontra memiliki argumen. Pertama, bertentangan dengan UU. Pasal 28 UUD 1945 yang diperbaiki menjadi Pasal 28 A setiap orang berhak untuk hidup dan berhak mempertahankan hidup dan kehidupannya. Diperkuat Pasal 28 I (1) UUD 1945 hak untuk hidup, hak untuk tidak disiksa, hak kemerdekaan pikiran dan hati nurani, hak beragama, hak untuk tidak diperbudak, hak diakui sebagai pribadi di hadapan hukum, dan hak untuk tidak dituntut atas dasar hukum yang berlaku surut adalah hak asasi manusia yang tak dapat dikurangi dalam keadaan apa pun. Pasal 9 UU Nomor 39 Tahun 1999 tentang HAM (1) setiap orang berhak untuk hidup, mempertahankan hidup, dan meningkatkan taraf kehidupannya; (2) setiap orang berhak hidup tenteram, aman, damai, bahagia, sejahtera lahir dan batin; (3) setiap orang berhak atas lingkungan hidup yang baik dan sehat. Kedua, hukuman yang kejam dan tidak manusiawi. Ketiga, rapuhnya 
sistem peradilan pidana sehingga terbuka peluang kesalahan penghukuman. Keempat, tak sejalan dengan arah pembaruan hukum pidana. Hukuman mati menekankan aspek balas dendam (retributive). Padahal arah hukuman pidana adalah ke arah keadilan restoratif (restorative justice). Kelima, efek jera terhadap hukuman mati dianggap mitos. Keenam, penderitaan akibat hukuman mati dialami korban dan keluarganya (covictims). Ketujuh, mengancam perlindungan WNI di luar negeri. Kedelapan, merugikan Indonesia dalam pergaulan dunia internasional. Reputasi internasional sebuah Negara menjadi salah satu komponen kekuatan diplomasi Negara. Hal ini menurut Ken Matahari (Staf Amnesty International di Sydney Australia) bisa memengaruhi berbagai hal, mulai dari perdagangan dan investasi hingga perlakuan terhadap WNI di negara lain. Hukuman mati di Indonesia akan mencoreng legitimasi moral Indonesia untuk mendesak Negara lain untuk menghapus hukuman mati. Hal ini menjadi dilema Indonesia bila melindungi WNI dari hukuman mati di luar negeri. Pada Mei 2015, diperkirakan ada 208 WNI terancam hukuman mati di mancanegara. Kesembilan, kecenderungan dunia meninggalkan hukuman mati. Komisioner Hak Asasi Uni Eropa Stavros Lambrindis menyatakan, tahun 1945 hanya ada 8 negara yang menghapus hukuman mati dan tahun 2015 meningkat menjadi 150 negara. Pemerintah Republik Demokratik Kongo dan Republik Afrika Selatan menyatakan menghapus hukuman mati. Pernyataan tersebut terungkap dalam Kongres Antihukuman Mati Sedunia ke-6 di Oslo, Norwegia Rau 22 Juni 2016 (Kompas, 23 Juni 2016).

Kompleksnya persoalan hukuman mati menurut Ken Matahari, ada orang yang tak bersalah dieksekusi mati, telah divonis hukuman mati dan dipenjara selama bertahun-tahun sambil menunggu eksekusi mati, beberapa tahun kemudian terbukti tak bersalah. Hasil riset The Proceedings of the National Academy of Science yang diterbitkan tahun 2014, hampir 4 persen kasus hukuman mati di Amerika melibatkan orang yang akhirnya terbukti tak bersalah. Artinya, dari 100 orang yang dihukum mati, 4 di antaranya tak bersalah. Tak ada sistem hukum yang sempurna dan bebas dari kesalahan. Kematian bersifat mutlak, final, dan tak dapat diubah. Tak ada bukti empiris yang menunjukkan hukuman mati bisa memberi efek 
jera dan menurunkan tingkat kriminalitas secara lebih efektif dibandingkan dengan bentuk hukuman lain, misalnya hukuman seumur hidup. Ada tiga kategori hukuman mati di Indonesia, yakni pembunuhan berencana, terorisme, dan pengedaran obat-obatan terlarang..

Menurut Ken Matahari, hukuman mati dalam Kovenan Internasional Hak-hak Sipil dan Politik hanya bisa diberlakukan untuk kasus kejahatan paling serius. Pengedaran narkoba adalah masalah yang serius yang patut untuk diperangi. Berdasarkan hukum internasional, kejahatan ini tidak dikategorikan dalam definisi kejahatan paling serius. Dalam hukum internasional, definisi kejahatan paling serius adalah kejahatan yang sengaja menyebabkan kematian secara langsung dari tindakan kejahatan itu. Motifasi pengedar narkoba adalah mendapatkan keuntungan finansial, sehingga kejahatan narkoba tak masuk dalam kategori kejahatan paling serius. Ken menambahkan, kompleksnya masalah kriminal di Indonesia seperti pengedaran narkoba perlu penanganan khusus, yakni penegakan hukum harus dibenahi, sistem keamanan bandara dan perbatasan harus diperkuat, rehabilitasi terhadap korban narkoba harus diprioritaskan, korupsi dalam penegakan hukum harus diberantas, dan pendidikan anti narkoba harus mendapatkan perhatian serius dari pemerintah dan masyarakat.

Bagi yang pro hukuman mati, hukuman mati tertuang dalam KUH Pidana, UU Nomor 31 Tahun 1999 tentang Pemberantasan Tindak Pidana Korupsi, UU Nomor 15 Tahun 2003 tentang Pemberantasan Tindak Pidana Terorisme, UU Nomor 26 Tahun 2000 tentang Pengadilan HAM, dan UU Nomor 5 Tahun 1997 tentang Psikotropika. Merujuk hasil putusan Mahkamah Konstitusi pada 30 Oktober 2007 atas pengujian Pasal 80 UU Nomor 22 Tahun 1997 tentang Narkotika yang memuat sanksi pidana mati terhadap UUD 1945. MK memutuskan bahwa hukuman mati dalam UU Narkotika tak bertentangan dengan hak hidup yang dijamin UUD 1945 karena jaminan hak asasi manusia dalam konstitusi mesti dipakai dengan menghargai dan menghormati hak asasi orang lain demi berlangsungnya ketertiban umum dan keadilan sosial. Dengan demikian, hak asasi manusia harus dibatasi dengan instrumen UU, yaitu hak untuk hidup itu tidak 
boleh dikurangi, kecuali diputuskan oleh pengadilan. Alasan lain dari MK, Indonesia telah terikat dengan konvensi internasional narkotika dan psikotropika yang telah dirativikasi menjadi hukum nasional (UU Narkotika). Indonesia berkewajiban menjaga dari ancaman jaringan peredaran gelap narkotika skala internasional yang salah satunya dengan menerapkan hukuman yang efektif dan maksimal.. Indonesia pun mengakui bahwa kejahatan narkotika sebagai kejahatan luar biasa terhadap kemanusiaan (extra ordinary crime) sehingga penegakan hukumnya butuh perlakuan khusus. Dengan demikian, Indonesia tidak melanggar perjanjian internasional apa pun, termasuk Konvensi Internasional Hak Sipil dan Politik (ICCPR) yang menganjurkan penghapusan hukuman mati. Mahkamah Konstitusi (MK) menegaskan, Pasal 6 ayat 2 ICCPR membolehkan masih diberlakukannya hukuman mati kepada negara peserta, khusus untuk kejahatan yang paling serius. Keseriusan itu dapat dinyatakan bahwa dampak narkoba dalam kehidupan yang membahayakan. Dari aspek jaringan global, jaringan internasional yang memasok narkoba ke Indonesia yakni Tiongkok, Nigeria, Pakistan, Iran, Malaysia, Thailand, Afrika Selatan, Taiwan. Pelaksanaan eksekusi mati pelaku narkoba di Indonesia mendapat seruan penghentian oleh Uni Eropa. Dalihnya, hukuman mati itu tidak mengurangi jera pelaku. Data Direktorat Tindak Pidana Narkoba Bareskrim Polri, ada 40.253 kasus narkoba terhitung akhir Juli 2016.

\section{J. Kesimpulan}

Pemerintah (Kementerian Sosial, Kementerian Kesehatan, dan Badan Narkotika Nasional/BNN) menargetkan merehabilitasi 200.000 pecandu atau pengguna narkoba di pusat rehabilitasi atau pendampingan pada tahun 2016, meski anggaran pemerintah hanya untuk 15.000 pecandu. Sebanyak 700 narapidana kasus narkoba mengikuti program rehabilitasi therapeutic community selama tiga bulan sejak Selasa 10 Mei 2016. Program itu hasil kerja sama anatara LP Narkotika Kelas II A Jakarta dan BNN Provinsi DKI. Therapeutic community merupakan salah satu metode rehabilitasi dengan memberikan pembelajaran secara berkelompok didampingi konselor dan psikolog kepada peserta dalam menghadapi permasalahan. Kegiatan yang diselenggarakan berupa konseling, kegiatan 
kelompok, rekreasional, vokasional, keagamaan, seminar, dan olahraga (Kompas, 11 Mei 2016).

Ketegasan pemerintah RI dalam mengeksekusi mati bagi pengguna, penyelundup, dan pemasar narkoba setelah divonis mati hakim mendapat perlawanan dari Australia, negara yang warganya menjadi obyek eksekusi. Akan tetapi, tatkala pemerintah RI tetap kukuh mengeksekusi, Australia pun melemah dalam perlawanannya. Hal ini sebagai penanda bahwa ketegasan mengeksekusi suatu keharusan agar anak bangsa tidak menjadi sasaran narkoba yang membahayakan kehidupan anak bangsa. Ketegasan pemerintah realitanya tak menyurutkan pelaku yang mengedarkan, menjual, dan menyelundupkan narkoba di Tanah Air. 
Moh. Rosyid

\section{DAFTAR PUSTAKA}

An-Na'im, Abdullah Ahmed. Dekonstruksi Syariah Wacana Kebebasan Sipil, HAM, dan Hubungan Internasional dalam Islam. LKiS dan Pustaka Pelajar: Yogyakarta, 1990.

Basyir, Ahmad Azhar. Refleksi atas Persoalan Keislaman Seputar Filsafat, Hukum, Politik, dan Ekonomi. Mizan: Bandung, 1996.

Jahar, Asep Saepuddin, dkk. Jamhari Makruf dan Tim Lindsey (Ed). Hukum Keluarga, Pidana, dan Bisnis. Prenada Media Grup: Jakarta, 2013.

Murdiana, Elfa. Hukum dan Perundang-undangan Deskripsi tentang Hukum dan Peraturan Perundangan yang Berlaku di Indonesia. Idea Press: Yogyakarta, 2015.

Matahari, Ken. Mengakhiri Hukuman Mati. Kompas, 30 Juli 2016.

Nurdin, Adnil Edwin. Madat Sejarah, Dampak Klinis,dan Penanggulangannya. Mutiara Wacana: Semarang. 2007.

Ridwan. Limitasi Hukum Pidana Islam. Walisongo Press: Semarang. 2008. 